Res Pública Revista de Historia de las Ideas Políticas

ISSN: 1131-558X

\title{
Estancia y carácter de apátrida. Un previo a propósito de "cuestiones políticas" en y desde Heidegger
}

\author{
Guillermo Moreno Tirado* \\ Recibido: 16 de mayo de 2020 / Aceptado: 15 de junio de 2020
}

Resumen. En este trabajo se presenta una exposición sintética de un elemento previo a las cuestiones política en la obra de Heidegger que critica, implícitamente, el uso de su obra para defender propuestas que pretendan fundar comunidades en nuestro tiempo, los límites internos (al propio planteamiento de Heidegger) de los intentos heideggerianos por proponer una fundación de este tipo (ya sea bajo el nombre de estado, comunidad, pueblo, etc.) y de aquellos intentos semejantes que no tomen en consideración a este autor. El elemento previo es el problema de la "patria" (die Heimat) y su constitución de la "estancia" (der Aufenthalt) del hombre y el "carácter apátrida" (die Heimatlosigkeit) inherente al "estado civil" moderno y a la moderna "sociedad civil".

Palabras clave: Heidegger; estancia; carácter apátrida; política; estado civil.

\section{[en] Stay and Homelessness. A Preview of "Political Issues" in and from Heidegger}

\begin{abstract}
This paper presents a synthetic exposition of a previous element to the political questions in Heidegger's work that criticizes, implicitly, the use of his work to defend proposals that try to found communities in our time, the internal limits (to Heidegger's own approach) of the Heideggerian attempts to propose a foundation of this type (either under the name of state, community, people, etc.) and of those similar attempts that do not take into consideration this author. The previous element is the problem of the "homeland" (die Heimat) and its constitution of man's "stay" (der Aufenthalt) and the "homelessness" (die Heimatlosigkeit) inherent in the modern "civil state" and modern "civil society".
\end{abstract}

Keywords: Heidegger; Stay; Homelessness; Politics; Civil State.

Sumario. 1. Introducción. 2. La cuestión judía en la tradición alemana: de Lessing a Herder. 3. Ilustración y romanticismo frente a la historia: un balance. 4. Consideraciones finales. 5. Bibliografía.

Cómo citar: Moreno Tirado, G. (2020). Estancia y carácter de apátrida. Un previo a propósito de "cuestiones políticas” en y desde Heidegger. Res Pública. Revista de Historia de las Ideas Políticas, 23(1), 203-215.

\section{Introducción}

El trabajo que aquí se presenta pretende exponer sintéticamente ciertos desarrollos sobre los que se asientan lo que podríamos llamar "cuestiones políticas" en y desde Heidegger y, en este sentido, lo que queremos plantear tiene carácter previo. Esas "cuestiones” están, a nuestro juicio, marcadas por dos momentos que se concentran en el intento de comprensión de lo que significó el proyecto pólis y en cómo queda ese proyecto cuando nos encontramos ante Estados modernos. El primero es el que abarca la etapa del Rectorado y la separación de esta etapa, que se produce a partir de la lectura se- ria de Hölderlin y Nietzsche. Así, ya en el primer curso sobre Hölderlin (sobre los himnos Germania y El Rin), en el que se puede considerar que todavía pervive cierto convencimiento de lo que se plantea en la etapa del Rectorado, y en el curso Introducción a la metafísica de 1935, cuando esa pretensión se puede considerar abandonada, encontramos las reflexiones de Heidegger sobre la pólis y el Estado moderno que luego serán retomadas, por ejemplo, en el curso sobre Parménides y en el curso sobre El Ister de Hölderlin. Estos cursos pertenecen a lo que podemos llamar el segundo momento que comprendería, además, a nuestro juicio, los textos en los que Heidegger se confronta con Ernst Jünger y aquellos en

Universidad Complutense de Madrid

guigom01@ucm.es

Como se sabe, recogidos en el tomo 16 de la Gesamtausgabe; M. Heidegger, Gesamtausgabe, Bd. 16, Rede und anderen Zeugnisse eines Lebensweges, Frankfurt am Main, Vittorio Klostermann, 2000, pp. 79-338 (en adelante, la obra de Heidegger se citará siempre por esta edición como GA, número del volumen, título del texto dentro del volumen o nombre del volumen, si fuera necesario, y página), junto al primer todo de los Cuadernos negros, al menos las "Reflexiones" de los primeros años (GA 94, Überlegungen II-IV, pp. 1-305). 
los que el asunto es la técnica o el problema de en qué mundo estamos ${ }^{2}$.

Ahora bien, conste que no pretendemos establecer divisiones en el trabajo de Heidegger, sino que hablamos de dos momentos porque en el primero hay todavía cierta "esperanza" de poder fundar otro tipo de Estado moderno: uno que no esté basado en la organización calculadora, sino en el reconocimiento de las particularidades de un "pueblo", esto es, en contenidos concretos de aquellos que pertenecerían a ese Estado, y en la apropiación de un "destino" en la forma de un "proyecto político", esto es, la constitución o apropiación de ese "pueblo" como comunidad ${ }^{3}$, etc. Esta pretensión, finalmente, parece abandonarse en estos términos o, al menos, en el modo de su realización, y, entonces, hablamos de un segundo momento en el cual, la fundación de ese "otro Estado" parece postergarse, es decir, parece que Heidegger entiende que no va a ocurrir mientras él viva, ni tampoco en mucho tiempo, y la reflexión se centra, entonces, en las raíces o los presupuestos del Estado moderno a diferencia de la pólis griega, como explícita

Especialmente, nos estamos refiriendo a lo que podemos encontrar en La pregunta por la técnica, Ciencia y meditación, Superación de la metafísica (GA 7, pp. 5-36, pp. 37-65 y pp. 67-98), La época de la imagen del mundo, ¿Para qué poetas? (GA 5, pp. 75-113, pp. 269320), Hacia la pregunta por el ser (GA 9, pp. 385-426), La pobreza, en Heidegger Studien, 10, 1994, pp. 5-11 y los esbozos que se encuentran en GA 73.1, Zum Ereignis-Denken, pp. 703-712, así como en Aportes a la filosofía (GA 65; especialmente la "segunda fuga", "La resonancia", pp. 107-166) y los seminarios sobre Jünger (GA 90, Zu Ernst Jünger). Hay que considerar en un apartado prácticamente independiente El origen de la obra de arte (GA 5, pp. 5-74), ya que este texto puede considerarse, junto con el curso Introducción a la metafísica de 1935 (GA 40), como un punto intermedio entre la etapa del Rectorado y la etapa que nos interesa aquí; esta etapa está marcada por el inicio de la lectura de Hölderlin, que se recoge especialmente en GA 39; para una lectura de todo el camino y del problema "político" en Heidegger en su primera lectura de Hölderlin, cf.: M. E. Vázquez, "Heidegger-Hölderlin / Filosofía-poesía", en J. Marrades y M. E. Vázquez (eds.), Hölderlin. Poesía y pensamiento, Valencia, Pre-Textos, 2001, pp. 163-176. Cf., asimismo, para las "cuestiones políticas" en Heidegger: R. Schürmann, Le principe d'anarchie: Heidegger et la question de l'agir, París, Seuil, 1982; S. Vietta Heideggers Kritik am Nationalsozialismus und an der Technik, Tübingen, Niemeyer, 1989; D. Janicaud, L'ombre de cette pensé - Heidegger et la question politique, Grenoble: J. Millon, 1990.

En estas reflexiones suele referirse, normalmente, a los alemanes. Los alemanes son los destinatarios de la palabra de Hölderlin y aparecen como "herederos" del proyecto moderno, de su culminación o acabamiento. Sin embargo, en los textos de los años 50' recogidos en De camino al habla (GA 12), los "alemanes" son sustituidos por los "occidentales", de modo que el asunto del "pueblo" abarca a todos aquellos que se encuentran inmersos en el "proyecto Occidente". Los poetas que sigue leyendo Heidegger escriben en alemán, incluso Hölderlin sigue estando a la cabeza, pero la cuestión del "pueblo" ha dejado de estar fijada en una "nacionalidad" frente a las demás, para enfocarse en una situación histórica frente a otras. Dentro de esas "otras situaciones históricas" ya no está solamente la Grecia antigua, sino también la Asía Oriental o el "lejano Oriente" (China o la China antigua y Japón). Aunque no voy a desarrollar esto en concreto, creo que sí puede apreciarse que las reflexiones "políticas" de Heidegger que tienen, al principio, un marcado carácter "nacionalista" son las mismas que luego se utilizan para abarcar todo Occidente. Por consiguiente, creo que lo de menos es ese carácter "nacionalista". Esto, sin embargo, no quita que haya que seguir cuestionando el alcance y el sentido de esas reflexiones y no aceptarlas sin más; en otras palabras, creo que sigue mereciendo la pena preguntarse si la pretensión de "fundar Estado" es algo plausible cuando estamos instalados en desarraigo, o si con lo que hay que quedarse de la reflexión heideggeriana es con los límites "políticos" que implica ese desarraigo. pérdida de esa pólis y como perteneciente, este, a la técnica moderna y, por tanto, sostenido sobre la metafísica moderna de la subjetividad.

El momento que nos interesa es el segundo porque es en el que más se nota explícitamente la asunción heideggeriana del nihilismo ${ }^{4}$. Resumiendo el planteamiento de esos textos, digamos que Heidegger entiende que en nuestro tiempo la "política" ha quedado reducida a una expresión más de la "voluntad de poder", es decir, una expresión de la nihilidad en la cual estamos instalados y que ya sea en la forma "americana" de la democracia o en la forma "comunista-soviética" de la dictadura, ambos bloques están inmersos en una ignorada metafísica de la subjetividad, de manera que apenas alcanzan a ver el horizonte del problema. Ese problema lo encuentra Heidegger en el modo como sigue habiendo para nosotros desvelamiento (o sea, verdad), a saber, como técnica moderna, y en qué sentido tal desvelamiento hace que nos encontremos instalados en el Ge-stell, es decir, tal que todo lo que es, todo lo ente, se presenta como una "existencia en stock" disponible para su empleo en la forma de un "promover, explotar, extraer" (Fördern) que tiene como supuesto fundamental el intercambio general de todo con todo (que cualquier cosa es intercambiable, en principio, por cualquier otra, o sea, que se impone el concepto marxiano de mercancía ${ }^{5}$ ), y que nos permite dominar lo ente (ser independientes de ello o "emanciparnos"), pero que se cobra en retribución nuestra imposibilidad de estar de otra manera en el mundo que como empleables por y para ese mismo Ge-stell ${ }^{6}$. so y Alejandro Vigo, Buenos Aires, Editorial Biblios, 2005 y el texto de F. Duque, El cofre de la nada: deriva del nihilismo en la modernidad, Madrid, Abada Editorial, 2006.

La lectura de la filosofía de Marx que asumimos la tomamos de los trabajos: C. Ruiz Sanjuán, Historia y sistema en Marx. Hacia una teoría crítica de El capital, Madrid, Siglo XXI, 2019; M. Heinrich, ¿Cómo leer El Capital de Marx? Indicaciones de lectura y comentario del comienzo de El Capital, trad. César Ruiz Sanjuán, Madrid, Guillermo Escolar, 2018; C. Ramas San Miguel, Fetiche y mistificación capitalistas. La crítica de la economía política de Marx, Madrid, Siglo XXI, 2018; F. Martínez Marzoa, La filosofía de "El capital” de Marx, Madrid, Abada, 2018; y, El concepto de lo civil, Madrid, La Oficina, 2018; M. Nieto, Cómo funciona la economía capitalista, Madrid, Escolar y Mayo, 2015; este último polemiza con C. Fernández Liria y L. Alegre Zahonero, El orden de El Capital. Por qué seguir leyendo a Marx, Madrid, Akal, 2010. En otro orden, citamos también J. Derrida, Spectres de Marx, Paris, Éditions Galilée, 1993, pues creemos que con este trabajo hay que contar a la hora de volver a plantear el problema de la filosofía de Marx. Asimismo, este trabajo tiene en el horizonte el texto de Julián Santos Guerrero, Cuestiones de marco. Estética, política y deconstrucción, Madrid, Escolar y Mayo Editores, 2014, con quien entablamos la discusión de fondo.

Cf. I. Borges-Duarte, Arte e técnica em Heidegger, Rio de Janeiro, Via Verita, 2019, pp. 147-185, y de la misma: "La tesis heideggeriana acerca de la técnica", en Anales del Seminario de Historia de la Filosofia, 10, 1993, pp. 121-156; F. Schalow, "The «Ownmost Sway» of Technicity and Its Hermeneutic Guideline (Part I)", Heidegger Studien, 29, 2013, pp. 51-66 y "A Look at Recent Literature on Technicity, Machination, and the Turning: Part II", Heidegger Studien, 30, 2014, pp. 79-95; a propósito del Fördern, cf. H.-D. Bahr, "Das Wesen der Technik und das «andere Geschick». Ge-stell und Gegnet im Denken Martin Heideggers", Heidegger Studien, 29, 2013, pp. 89-120, especialmente por lo que respecta a cómo en este trabajo se asume una lectura del Idealismo alemán, que aquí no podemos desarrollar, en continuidad con Marx. Conste que a pesar de que no es lo mismo empíricamente lo que aparece como empleable 
El asunto de este trabajo no es demostrar que estamos en nihilidad, que estamos instalados en el Ge-stell -aunque siempre se tratará de poner de manifiesto en qué consiste que eso sea así-, sino, más bien, qué consecuencias con respecto a las "cuestiones políticas" puede tener que ese sea nuestro punto de partida. Las cuestiones previas de las que nos vamos a ocupar pretenden defender que el sentido de los desarrollos de las "cuestiones políticas" en y desde Heidegger pueden interpretarse precisamente para mostrar esas consecuencias.

Antes de plantear el punto de partida para este trabajo, debemos advertir que la circunstancia de que el tema sea "algún asunto" de, en o desde Heidegger no quiere decir simplemente que se pretenda dar una lectura de Heidegger como quizá cabe hacer una lectura de Kant. Esto no solo es debido a que falte todavía una crítica filológicamente suficiente del corpus Heidegger, el cual ni siquiera está cerrado, sino que, además, falta también la suficiente distancia. Respecto a esto, hay que decir que ciertos autores han demostrado que, para ciertos tramos de ese corpus, la lectura ya es posible ${ }^{7}$, sin embargo, también esas lecturas muestran sus limitaciones sobre otros tramos; limitaciones normalmente reconocidas y que no devalúan en nada dichas lecturas, sino que hacen evidente lo que tratamos de advertir-advertencia que hace, además, que el valor de estas lecturas resulte innegable-, que todavía no hay distancia suficiente para con ese corpus. La otra cara de esta advertencia también la muestra el grueso de la literatura sobre Heidegger ${ }^{8}$, a saber, que muchos de sus textos son todavía para nosotros lugar de discusión y no solamente fuente de la historia del pensamiento.

En lo que sigue, nos moveremos en la ambigüedad inherente a que este sea el estado de cosas en relación con el corpus Heidegger, de modo que con respecto a alguna cuestión se procederá en discusión mientras que con otras se estará tratando de hacer lectura sin que se haga evidente todo el tiempo esta distinción. Creemos

por el Ge-stell en términos de "propietarios" del "capital y medios de producción", que de la "fuerza de trabajo", sí lo es estructuralmente, esto es, para el Ge-stell. Que sea lo mismo es lo que hace del discurso de esta sociedad civil, sociedad burguesa, sociedad moderna o como quiera que se lo llame, un discurso perverso (sobre ello, esperamos que pronto vea la luz el trabajo de R. C. Fasolino, "De las (im)posibilidades del vínculo. Algunas consideraciones a partir del «discurso del capitalista» de J. Lacan", todavía inédito).

Limitándonos al ámbito de habla hispana, nos referimos principalmente a la línea de interpretación que han sostenido autores como Ramón Rodríguez, Arturo Leyte, Alejandro Vigo, Manuel Jiménez Redondo, Manuel E. Vázquez García, Félix Duque, Paloma Martínez Matías y en otra línea Felipe Martínez Marzoa, entre otros. Es decir, nos referimos a la lectura que recorre con solvencia aquellos tramos de la obra que se consideran como una primera etapa y que al ir sobre lo que se considera como "segunda etapa" tratan de mantener tanto la distancia crítica como la pretensión de que lo allí dicho no se convierta en una suerte "nueva religión".

8 Gran parte de ese grueso, por cierto, no demuestra ser "literatura para interpretar" sino fuente de discusión. Nos referimos ahora a los trabajos de Levinas, Gadamer, Foucault, Derrida, Deleuze, Agamben, Roberto Esposito, parte de lo que ha podido escribir Vattimo, Lacoue-Labarthe, etc. No pretendemos decir que estos autores no hayan interpretado a Heidegger, sino que su trabajo tiene que ver más bien con una confrontación o discusión prácticamente directa con él, la cual es fructífera en sí misma, aunque, evidentemente, solo si se la considera como tal. que hacer esa distinción puede resultar en muchos momentos arbitrario y que desvirtúa la fuerza que, de todos modos, tiene la ambigüedad.

\section{Punto de partida}

Partimos de la constatación de que la "patria", la "patria chica", el "suelo natal" o el "hogar", aparece en Heidegger como un problema, como una cuestión, por consiguiente, no como algo con lo que uno simplemente se encuentra, sino, como algo que, a pesar de que uno pueda tener noticia de ello (esto es, tener cierta concepción de qué es eso), hay que sacar a la luz. Mi interpretación es que, al ser sacada a luz, la patria se muestra como algo que no se cumple o que se pierde o se está perdiendo y, en todo caso, como algo que quizá uno puede querer construir, por ejemplo, pretendiendo construir una comunidad, un estado, un movimiento político, etc., pero no como algo que haya. Por tanto, mi "tesis" es que tenemos que partir de ese estatuto de "pérdida del hogar, de la patria chica, del suelo natal", etc., en definitiva, de desarraigo (die Entwurzelung) para atender a las consecuencias políticas que ello pueda tener.

Dado que esta constatación nos lleva a considerar desde el principio que lo problemático de la "patria" es principalmente que no la hay, lo que cuestionamos es los visos de éxito que puede tener la pretensión de construirla, fundarla o reivindicarla (sea del signo que sea, esa pretensión), por tanto, qué perspectivas de éxito podría tener incluso Heidegger allí donde él mismo se posiciona como alguien que pretende justamente esa "construcción", "fundación" o "reconstrucción"9.

La interpretación que pretendo sostener es que, de todas formas, Heidegger atiende a esta cuestión en la forma de algo perdido, algo que ya no tiene lugar y que las noticias que tenemos de ello no son sino de ese perderse o estar en pérdida que, quizá por el empeño de muchos, se percibe como algo todavía en proceso, pero que visto desde el ángulo de lo que pudiera querer decir que sí la hubiese, que sí hubiese "suelo natal", "patria", etc., demostraría, más bien, que ello mismo ya no lo hay ${ }^{10}$.

\footnotetext{
Esta es la situación, al menos, en 1933/34, y desde luego en los textos del "Rectorado" y, sobre todo, en el curso de esta fecha sobre los himnos de Hölderlin Germania y El Rin, GA 39. Vaya por delante que, dado que la cuestión aparece, de todas formas, como "problema" en Heidegger, independientemente de que él mismo en algún momento se posicione en esa pretensión, de ello siempre cabrá hacer una sana "puesta entre paréntesis", por cuanto el abordaje de la cuestión como "problema" puede seguir siendo interesante en la medida en que, como se ha dicho en el apartado anterior, uno siga estando en la tarea de asumir la nihilidad.

10 Esta interpretación está sustentada, especialmente, en la constatación de que la tarea de asumir el nihilismo y, por tanto, la metafísica tiene que ver con un "peregrinaje" (Wanderschaft) que consiste en una "llegar a sentirse en lo hogareño" (Heimischwerden) o una "vuelta al hogar" (Heimkunft) que se lee en los poemas tardíos de Hölderlin (cf. GA 53, Hölderlins Hymne "Der Ister", pp. 11-62; pero el asunto se mantiene durante todo el curso; y GA 4, "Heimkunft / An die Verwandten”, pp. 9-32). Si hay que emprender un camino de regreso es porque en ello no se está y es muy notorio que este regreso tenga que ver un recordar (Andenken) que, en principio, no termina, no logra construir una figura, sino que se traduce en una disposición a "estar a la espera en sosiego, en abandono o en desasimiento (Gelassenheit)".
} 
La pregunta, de todas formas, insisto, será si eso mismo es constitutivo de una comunidad (una que pudiera ser nuestra) o de la imposibilidad de pensar en que la comunidad sea algo que uno pueda construir y, entonces, qué consecuencias podría tener lo uno o lo otro.

Lo que pretendo, en primer lugar, en este trabajo es ocuparme de este punto de partida, tratando de sostener argumentativamente la posición interpretativa que lo toma como tal, a saber, que toma la "patria", el "hogar", el "suelo natal", como algo que constituye un problema. En segundo lugar, y dado que con ello uno puede sacar consecuencias, se pretenderá dar algún norte para la cuestión general de en qué queda la "política" desde esta interpretación de Heidegger.

Pues bien, en Carta sobre el "Humanismo" encontramos precisamente este problema para formular lo que expresa die Lichtung (el claro), lo que "garantiza y preserva la proximidad al ser"11, a saber, la proximidad al tener lugar del tener lugar de las cosas, y que, en ello, "en el claro del «aquí», habita el hombre en cuanto ex-sistente, sin que sea ya hoy capaz de experimentar propiamente ese habitar ni de asumirlo"12. A esta "proximidad «del» ser" se la llama (desde el poema de Hölderlin Heimkunft que Heidegger comenta ${ }^{13}$ ) "patria"; pero, "la esencia de la patria ha sido nombrada [nos dice Heidegger] con la intención de pensar el desterramiento o el carácter apátrida [Heimatlosigkeit] del hombre moderno"14. La tarea es, por tanto, pensar, en primer lugar, la patria desde allí donde la hubo y donde, por primera vez, se notó su pérdida, a saber, desde lo griego ${ }^{15}$.

Tomaré, por tanto, este camino, partiendo de un breve comentario de Heidegger al fragmento 119 de Heráclito y a través de la traducción/interpretación de una de sus palabras ${ }^{16}$. Esa traducción/interpretación va a sacar a luz el presupuesto de la interpretación heideggeriana de la "patria" y en qué medida, el esfuerzo de pensarla tiene la vista puesta en pensar nuestro carácter apátrida,

\section{GA 9, Brief über den “Humanismus”, p. 337.}

Ibidem.

3 Cf. GA 4, "Heimkunft / An die Verwandten", pp. 9-31.

14 GA 9, Briedf über den “Humanismus”, p. 338; a propósito de ello, cf. F. Volpi, “«Noi senza patri». Heidegger e la «Heimatlosigkeit» dell'uomo moderno", Revista Portuguesa de Filosofia, 59, 4, 2003, pp. 1261-1263; F. Ricci, "Gagner la Heimatlosigkeit", Heidegger Studien, 24, 2008, pp. 61-102.

15 Esta estrategia la toma Heidegger de Hölderlin, de su lectura de la carta a Böhlendorf del 4 de diciembre de 1801, F. Hölderlin, Sämtliche Werke "Frankfurter Ausgabe", Historisch-kritische Ausgabe herausgegeben von D. E. Sattler, Band 19, Stammbuchblätter, Widmungen und Briefe II, hrsg. v. D. E. Sattler und Anja Ross, Frankfurt am Main, Stroemfeld Verlag, 2007, pp. 492-493; se trata de la cuestión del tránsito o el peregrinaje por lo ajeno ("el fuego del cielo", lo propio de lo griego), para aprender a usar libremente lo propio, "la claridad de la exposición".

16 La lectura de Heidegger de Heráclito se expone en detalle en GA 55, Heraklit; GA 15, Martin Heidegger - Eugen Fink: HERAKLIT, pp. 9-263 y GA 7, Logos (Heraklit, Fragment 50), Moria (Parmenides, Fragment VIII. 34-41), Aletheia (Heraklit, Fragment 16), pp. 211-234, pp. 235-161 y pp. 263-288. Conste que esta lectura no es separable de su lectura de los griegos y de Grecia en general (cf. F. Martínez Marzoa, "El sentido y lo no-pensado. (Apuntes para el tema «Heidegger y los griegos»)", en F. Martínez Marzoa, De Grecia y la Filosofía, Murcia, Secretariado de Publicaciones, Universidad de Murcia, 1990, pp. 41-82). o sea, el que la patria solo acontece en pérdida o como perdida.

\section{El fragmento 119 de Heráclito}

En Carta sobre el Humanismo, encontramos el siguiente comentario al fragmento 119 de Heráclito ${ }^{17}$ :

Dicha sentencia de Heráclito reza así (frag. 119): 讯o $\alpha v \vartheta \rho \omega ́ \pi \omega \delta \alpha i ́ \mu \omega v$. Suele traducirse de esta manera: "Su carácter es para el hombre su demonio". Esta traducción piensa en términos modernos, pero no griegos. El término $\tilde{\eta} \vartheta$ o $\varsigma$ significa estancia [Aufenthalt], lugar del morar [Ort des Wohnens]. La palabra nombra el ámbito abierto donde mora el hombre. Lo abierto de su estancia deja aparecer lo que le viene reservado a la esencia del hombre y en su venida se detiene en su proximidad [in seiner Nähe sich aufhält]. La estancia del hombre contiene y preserva [enthält und bewahrt] el advenimiento de aquello que le pertenece al hombre en su esencia. Eso es, según la palabra de Heráclito, el dios. Así pues, la sentencia dice: el hombre, en la medida en que es hombre, mora [wohnt] en la proximidad de dios [in der Nähe Gottes; en la presencia, la cercanía de dios o de los dioses $]^{18}$.

Hemos dicho que la situación para la cual podemos decir que todavía se percibe la "patria" como "comunidad" y ello como algo que hay, como algo que tiene contenido, que se hace valer y, por tanto, que constituye "hogar", "suelo natal", etc., es la Grecia antigua19. Para captar esto, hay que esforzarse por "pensar en términos griegos" y, de momento, tenemos que tratar de hacernos con esos términos. Ahora bien, quizá hay que advertir que lo que haremos no solo no será lo que podemos interpretar que hacía Heráclito, sino que ni siquiera se tratará de que estemos tratando de entender griego o lo griego. Lo que haremos $-\mathrm{y}$ en lo que vamos a insistir en el apartado 4- será traducir, y todo el esfuerzo será que esa traducción no sea "en términos modernos, sino griegos". En otras palabras, de lo que se trata es de en-

17 Heidegger también se ocupa de este fragmento en GA 55 Heraklit, pp. 200-225.

18 GA 9, Brief über den "Humanismus", p. 354 (se ha consultado la traducción: Hitos, trad. H. Cortés y A. Leyte, Madrid, Alianza Editorial, 2014). Respecto a la cuestión del "daimon" y para lo que sigue a continuación, cf. F. Martínez Marzoa, Historia de la filosofia antigua, Madrid, Akal, 1995, en especial el capítulo "V. Heráclito", pp. 35-43 y el apartado "XV.2. Lo divino", pp. 98-102; también, del mismo autor: Ser y diálogo. Leer a Platón, Madrid, Itsmo, 1996, en especial el capítulo "12. El daímon” pp. 125-131, así como para la cuestión de qué pueda significar el que "todo esté lleno de dioses", cf. El saber de la comedia, Madrid, Antonio Machado Libros, 2005; El decir griego, Madrid, Antonio Machado Libros, 2006.

19 Debe estar a la vista todo lo que plantea Paloma Martínez Matías en sus trabajos: "De la «pólis» al estado moderno: una aproximación al problema de lo político en Heidegger", Anales del seminario de historia de la filosofia, 32, 2, 2015, pp. 451-475 y "Producto y mercancía: sobre la constitución ontológica de la modernidad a partir de Heidegger y Marx", Logos: Anales del Seminario de Metafísica, 47, 2014, pp. 199-225 y "La cuestión política en el capitalismo neoliberal global", Res Publica: revista de historia de las ideas politicas, 22, 2, 2019, pp. 511-531. Hablamos desde los resultados de estos trabajos y tratando de dialogar con ellos para continuar hacia otras cuestiones (algunas de las cuales también las ha trabajado Martínez Matías). 
tender la distancia con la situación griega, es decir, reconocerla. A ese ejercicio lo llamamos, con Heidegger, hacer hermenéutica (o fenomenología-hermenéutica) y es, quizá, el más teórico posible y, precisamente por ello, el que más posibilidades de orientación nos da para con nuestro mundo.

Ahora bien, lo que, entonces, no haré (con Heidegger) será asumir de partida la traducción escolar o tradicional de êthos por "ética", "moral", "costumbres" o "carácter", ni tampoco relacionaremos inmediatamente el êthos con lo que escolar y tradicionalmente se denomina "política" o "sociedad" (ni tampoco "sociedad civil"), a pesar de que, de alguna manera, eso que tradicionalmente se ha tratado de recoger bajo esos términos en la modernidad es lo que tendré a la vista, pues es en lo que, presumiblemente, queremos orientarnos.

Digo que esto será lo que no haré porque de lo contrario no tendremos orientación para con esas cuestiones. Insisto: con esas, con las nuestras, con nuestras cuestiones "ético-políticas", "sociales" (y de economía política), de "nuestras costumbres", "morales" o "de carácter", no con las griegas, las cuales, de todas formas, no entendemos. Para ganar orientación en ellas, más nos vale que el ejercicio teórico sea todo lo serio que pueda ser, es decir, para nuestro caso, que la comprensión sea de la distancia con Grecia. Si hacemos esto, quizá nos orientemos en cuestiones nuestras (no griegas) y habremos dado cuenta, en último término, de algo nuestro (no griego) que, en el fondo, es lo que seguramente nos interesa. Así, pues, en lo que sigue se insistirá en este doble aspecto: reconocer la distancia y comprender nuestro horizonte. Empecemos por reconocer la distancia.

La palabra êthos, en la medida en que aparece en el fragmento de un dicente experto ${ }^{20}$, esto es, alguien que en su decir no dice simplemente esta o aquella cosa sino el "ser-cosa de las cosas", el decir mismo, y, por tanto, en la medida en que en la Grecia antigua no hay distinción entre algo así como la "esfera del decir" y la "esfera del acontecer", dice el fondo sobre el cual siempre ya se está, por tanto, la palabra êthos, digo, hay que leerla

20 Se considera que Heráclito escribe en prosa jónica y, en tal sentido, no es un poietés, pero debido al tramo histórico en el que nos encontramos (entre el siglo VI y V a.C., en Jonia), no podemos considerar que "escribir en prosa" fuese algo "no marcado" como podría ser en nuestro tiempo "escribir en prosa" y, desde luego, que Heráclito hiciese lo propio del theorós. En aquel tramo histórico, escribir sin marca de metro ni periodo y sin que haya ninguna otra marca en lo que nosotros llamaríamos sin más la "recitación” y la "puesta en escena" resulta tan marcado como todas esas otras marcas, precisamente porque para cuando surge la "prosa jónica", que haya esas otras marcas es lo "normal" cuando se trata de maestros en decir. En otras palabas, no es para nada obvio eso que nosotros llamamos "prosa" y, por tanto, pienso que Heráclito también pertenece a la tradición de los dicentes expertos a la que pertenece Homero y Píndaro, teniendo en cuenta que, al alargar tanto esta noción, ciertamente está perdido concreción. Digamos que esa concreción la encontraríamos en cada uno de los casos, por ejemplo, en Píndaro hablaríamos de mélos, en Homero de épos, etc., y desde luego podríamos agruparlos y diferenciarlos de Jenófanes, Hecateo y Heráclito, pero, según la interpretación que seguimos aquí, en algún punto habría que considerarlos tan unidos como para decir que todos los que hemos nombrado (y, por supuesto, otros más) son dicentes expertos a diferencia de dicentes triviales y que todos están en la estela iniciada por Homero, que es el que establece, por así decir, para nosotros, la "medida" de lo que debiera ser un maestro en decir. en función de la palabra daímon ${ }^{21}$. Esto se debe a lo siguiente.

Sabemos que la palabra daímon está emparentada semánticamente con la palabra theós y significa, en principio, algo así como "demonio", "duende", "dios" o incluso "divinidad", por tanto, sabemos que con ella se menciona, en general, algo que como tal pertenece a los dioses, esto es, esos que no mueren o que no cierran su figura con la muerte porque, por así decir, ya tienen figura propia, presencia acabada, en contraposición a los hombres, para los cuales la muerte es el cierre mismo de su figura. Ahora bien, en la medida en que existe esta cercanía semántica, un dicente experto (como es Heráclito) puede marcar una de ellas (sin que importe en principio cuál, es decir, sin que importe que otro dicente, o el mismo en otro momento ${ }^{22}$, pueda marcar con un sentido semejante la otra, lo cual quiere decir que en cada caso hay que ver cuál se marca y cómo) de tal modo que con ello ya no se pretenda meramente mentar lo que con la semántica de la palabra trivialmente se menciona. ¿Qué se pretende mentar entonces?

Si no es a lo que trivialmente refiere, será, entonces, a aquello que señala al referirlo, a saber, en este caso, del "dios" su venir a presencia, el "tipo" de comparecencia que tiene (lo que "hace" dios al dios, el "ser-dios" del dios). ¿En qué consiste este presentarse del dios? Para empezar en que no comparece, que, por ejemplo, se "oculta" en la cosa, de manera que es eso "oculto" lo que le da a esa cosa su presencia. La comparecencia del "dios" es, entonces, lo oculto en la presencia de la cosa; así, la presencia del "dios" tiene la forma del ocultamiento. En este sentido, eso oculto en la cosa es lo explícitamente señalado, irreductible, incomparable de la cosa, lo que hace a esa cosa esa y no otra y, por consiguiente, a eso mismo lo podemos llamar el venir a presencia de eso presente en cuanto tal; venir a presencia que, según lo dicho, no-comparece, pero que es lo que hace irreductible a eso que sí comparece ${ }^{23}$.

Irreductibilidad, inconmensurabilidad, presencia, es algo que podría investigarse de cada cosa, esto es, que cada una, precisamente en lo que la hace a esa una y no otra, es irreductible, incomparable, presente. Por consiguiente, la irreductibilidad que se señala en la medida en que se pretenda no mencionar a este o aquel daímon, sino a lo que hace daímon al daímon, implica señalar al "lo mismo" por el cual el día es día porque la noche es la noche, o sea, al "lo mismo" por el cual los hombres son hombres precisamente porque los dioses son dioses, a saber, a la distancia, a la diferencia, a la brecha, al vuelco que hay de lo uno a lo otro como algo inherentemente irreductible.

Ese "lo mismo" no compone en Grecia algo así como una figura de la unidad total de lo que hay, sino lo que en cada caso es precisamente irreductible de esto o aquello

\footnotetext{
Para una lectura clásica de la palabra êthos, cf. J. Schmidt, Ethos. Beiträge zum antiken Wertempfinden, Borna, 1944.

22 Y este es el caso aquí, Heráclito, en otro fragmento, marca precisamente theós, y Heidegger lo documenta en este mismo texto citando el pasaje de Aristóteles en el que se recoge: ê̂nai gàr kaì entaûtha theoùs; GA 9, Brief über den "Humanismus", p. 335.

23 Esto que se acaba de decir lo fundamentamos, por ejemplo, en el texto de Heidegger La cosa; GA 7, pp. 165-187.
} 
en cuanto tal. Dado que la palabra daímon, al ser marcada (diferenciándola, digamos, ad hoc, de theós), menciona no a uno u otro dios, sino a aquello que "hace" dios al dios - a saber, su desmedida, su carácter incomparable e irreductible, que es justamente en lo que consiste el venir a presencia mismo-, dice precisamente el "lo mismo" que se juega en que comparezca esto o aquello. Ahora bien, eso ya no es una cosa concreta, sino la comparecencia de las cosas, el tener lugar de una y otra y otra, el venir a presencia en cuanto tal, que precisamente por ser justamente eso, trivialmente no se tematiza, sino que en ello el griego se mueve. Como en la Grecia antigua esa comparecencia de las cosas es el cotidiano y normal andar envuelto en los asuntos, esta palabra (esta sentencia), diciendo la comparecencia de las cosas en cuanto tal, dice el fondo sobre el cual siempre se está. $\mathrm{O}$ dicho como lo diría Heidegger, dice el "ser".

Ahora bien, con Heidegger sabemos que el intento de decir el "ser", el suelo que siempre ya se pisa, el propio tiempo o como quiera que se lo formule, comporta, precisamente por intentar decirlo, su hundimiento. Decir la comparecencia, el venir a presencia de algo, implica fijar ese algo y, por consiguiente, no decir ya su comparecencia, su venir a presencia, sino su presencia, su quid; y decirlo comporta, a su vez, que su venida a presencia haya quedado atrás y, así, que, paradójicamente, esta ya no sea. Por consiguiente, decir el "ser", el propio tiempo, el juego al que siempre ya se está jugando, comporta segarse la hierba bajo los pies, abocarse al abismo, a la falta de suelo firme, etc. Y esto ocurre con toda su fuerza precisamente en la Grecia antigua, puesto que en esta situación histórica no hay diferencia entre decir las cosas y el acontecer de las cosas, esto es, esa indistinción de las "esferas" es el punto de partida. Cuando esta situación haya llevado hasta las últimas consecuencias sus esfuerzos por decir precisamente esta indistinción (que no será sino, hacer notar, finalmente, la diferencia), se segregarán ambas esferas y la situación histórica se hundirá.

¿Cómo logra, entonces, el fragmento decir el "ser", o sea, decirlo sin hundirse? Justamente no diciéndolo, es decir, no refiriendo el daímon a lo que propiamente es (el theós, la venida a la presencia misma), sino a otra cosa, a saber, a lo que de daímon haya (oculto) en anthropós: el fragmento marca con ello lo irreductible del "hombre" qua "hombre". Dicho de otro modo, el fragmento da un rodeo para decir huidizamente lo que no se puede decir, porque decirlo implicaría su pérdida, y lo que se perdería no sería el venir a presencia de una cosa, sino el venir a presencia mismo, esto es, "todo", "todo el negocio" en el que consiste "toda" la situación histórica.

El huidizo decir o el decir en un rodeo, logra precisamente decir no diciendo, decir callando lo que "no se puede decir", lo que al decirlo se pierde porque consiste en o pasa por lo que sea anthropós, de modo que es eso lo que "se dice". Al pasarle, por así decir, la pelota al anthropós, el suelo no se hunde; no todo es anthropós en griego, aunque hablando del anthropós, en concreto, de lo que en él es o hay de daímon, se habla del suelo sobre el cual siempre ya se está sin que al mismo tiempo se hunda. De este modo se mantiene el fragmento en el filo de la navaja y logra decir lo que "no se puede decir" no-diciéndolo.

En el fragmento, eso del anthropós que es daímon es lo que Heráclito llama êthos; êthos refiere, por tanto, a aquello que es el venir a presencia del anthropós, pero está dicho de tal modo que al hablar de eso, del êthos para el anthropós, se está refiriendo huidizamente al venir a presencia mismo, a la comparecencia en cuanto tal de las cosas, es decir, al daímon.

\section{Der Aufenthalt}

Pues bien, en el ejercicio de traducción/interpretación que nos propone aquí Heidegger, êthos se traslada como der Aufenthalt. En general, el significado inmediato del vocablo alemán der Aufenthalt es "la estancia", tanto en el sentido de "la duración en la cual uno está en este o aquel lugar", como en el sentido de "domicilio" y "residencia". Ahora bien, puede apreciarse en el texto citado que la elección de la palabra como traducción/ interpretación del término êthos ha estado marcada por el radical halt-, "apoyo", "sostén", "mantener"-que en sustantivo, der Halt, significa asimismo "alto", "parada" en un viaje- que también aparece en la palabra alemana para comportamiento (Verhalten) ${ }^{24}$ y para acción (Haltung); todo lo cual nos habla de nuestro "espacio" o "lugar" en el cual tenemos sostén, en el cual estamos "a salvo" o "protegidos" de la intemperie. Dado que este "lugar" no solo comporta un "espacio", sino también un "tiempo", a saber, el "tiempo" que dura la residencia o el domicilio y el "tiempo" que dura nuestro comportarnos y nuestra acción para "salvaguardarnos" de la intemperie, este "espacio-tiempo" no es el que menciona la física-matemática, sino el "espacio-tiempo" de juego de esa duración ${ }^{25}$. Más adelante, dice el mismo texto: " "Halt» significa en nuestra lengua "Hut»" ${ }^{26}$, y esta es otra palabra alemana para referir a "protección" y "custodia", la cual encontramos en die Hütte, la cabaña o la choza, que es una de las formas más elementales de abrigo (die Bergung ${ }^{27}$ ) y de construcción de esa "protección" y "custodia"28. En la línea del sentido de "estancia", el texto pone en primer plano la constatación de que "permite" (gewährt) la experiencia de lo "conservable" (Haltbaren), esto es, de lo que perdura, aquello que dura mientras se está en este o aquel lugar ${ }^{29}$, el cual no es cualquiera sino precisamente el de la morada, el del lugar que se ocupa, digamos, como "habitual", como

\footnotetext{
Cotidianamente decimos que "las formas hablan de uno", pues, por así decir, el modo como uno se "sostiene" son sus maneras de modo que nos sostenemos sobre nuestros comportarnos; uno se sostiene, es consistente, por cómo actúa, por cómo se comporta.

25 Heidegger se refiere a esto como el "espacio-de-juego-temporal" (Zeit-Spiel-Raum); cf., especialmente, GA 65, Beitäge zur Philosophie (Vom Ereignis), pp. 371-388.

26 GA 9, Brief über den "Humanismus", p. 361.

27 Esta es otra palabra que Heidegger pone en consonancia semántica estructural con Aufenthalt; cf., por ejemplo, GA 65, Beiträge zur Philosophie (Vom Ereignis), pp. 389-392.

28 Heidegger se ocupa de ello a propósito de su uso en Hölderlin, cf. GA 4, Hölderlin und das Wesen der Dichtung, pp. 35-38.

29 "Erste dieser Aufenthalt gewährt die Erfahrung des Haltbaren", GA 9, Brief über den "Humanismus", p. 361.
} 
"propio", o como aquel que, al menos, provisionalmente debe valer como tal; todo esto es traducción/interpretación de êthos (recuérdese: anthrópoi daímon).

Por otro lado, estas cuestiones ya habían sido traídas indirectamente en Ser y tiempo cuando Heidegger daba los primeros pasos en la analítica del Dasein:

El estar-en [in-sein] no se refiere a un espacial estar-eluno-dentro-del-otro de dos entes que están-ahí [subsistentes, Vorhandener], como tampoco el "en" originariamente significa en modo alguno una relación espacial de este género; "in" procede de innan-, residir [wohnen], habitare, quedarse en [sich aufhalten], "an" significa: estoy acostumbrado [ich bin gewohnt ${ }^{30}$ ], familiarizado con, suelo [hacer] algo [ich pfege etwas ${ }^{31}$ ]; tiene la significación de colo, en el sentido de habito y diligo. Este ente al que le es inherente el estar-en así entendido, lo hemos caracterizado ya como el ente que soy cada vez yo mismo. El vocablo alemán "bin" ["soy"] se relaciona con la preposición "bei" ["en", "en medio de", "junto a"]; "ich bin" ["yo soy"] quiere decir, a su vez, habito [ich wohne $e^{32}$, me quedo en [halte mich auf bei]... el mundo como lo de tal o cual manera familiar [Vertrauten, de confianza, íntimo]. "Ser", como infinitivo de "yo soy", es decir, como existencial, significa habitar en [wohnen bei]..., estar familiarizado con... Estar-en es, por consiguiente, la expresión existencial formal del ser del Dasein, el cual tiene la constitución esencial del estar-en-el-mundo ${ }^{33}$

Der Aufenthalt, al abarcar semánticamente la morada habitual, lo que "resguarda", etc., indica también lo que somos en la medida en que refiere a ese comportarnos que resguarda y conserva nuestro estar-en las cosas, en los asuntos, en lo que cotidianamente nos ocupa. En la medida en que es a eso $-\mathrm{y}$, sobre todo, a la manera como eso tiene lugar- a lo que llamamos familiar, de confianza, íntimo, etc., der Aufenthalt menciona también nuestro "hogar", donde residen aquellos que nos son de confianza y donde nosotros nos sentimos heimisch, "como en casa".

Tanto en Carta sobre el Humanismo como en otros textos $^{34}$ se pone en juego esta referencia de significaciones con la palabra alemana das Heim -arcaísmo para

30 La cuestión podría resumirse diciendo que la costumbre reside donde habito, donde tengo mi morada. De ahí que el modo como moro sobre esta tierra, es decir, como se dice más adelante en la cita, lo que soy, se desvele previamente en cierta estructura sin la cual, sea lo que fuere lo que viniera después, no se comprendería; este modo, en el recorrido de Heidegger, termina en los versos de Hölderlin: "Voll Verdienst, doch dichterisch, wohnet/ der Mensch auf dieser Erde"; "lleno de méritos, mas poéticamente, mora (o habita)/ el hombre sobre esta tierra"; cf. GA 7, “... dichterisch wohnet der Mensch ...”, pp. 189-208.

31 Eduardo Rivera añade "hacer" porque lo toma del texto de Jacob Grimm citado por Heidegger, cf. M. Heidegger, Ser y tiempo, trad. J. E. Rivera, Madrid, Trotta, 2009, p. 462.

32 Cf., a este respecto, GA 7, Bauen Wonhen Denken, pp. 145-164; donde la palabra del alto alemán buan, habitar, permanecer, residir (aufhalten) ha dejado su rastro en Nachbar (vecino), el que habita o ha construido en la proximidad, Nachgebur, Nachgebauer, y cómo este verbo está en relación sincrónica con el bin de ich bin, a través de $b h u$ y beo, etc.

33 M. Heidegger, Ser y tiempo, trad. de J. E. Rivera, op. cit., pp. 75-76 (cf. GA 2, Sein und Zeit, p. 73).

34 Cf. las referencias en la nota 12 de este trabajo. "casa"-, la cual significa, en general, "hogar", y de donde la lengua alemana forma die Heimat, que menciona lo que en castellano diríamos como "patria", "patria chica" o "terruño", la cual conforma campo semántico con die Vaterland, que es lo que traducimos aquí por "patria", en el sentido de "nación", y de donde, a su vez, aparece die Heimatboden (que utiliza Hölderlin), que traducimos por "suelo natal", y con la palabra das Hause, que es el término moderno para "casa" - de todas formas, una vez adoptados los términos en castellano, no pretendemos que sean sustituibles por vocablos alemanes, sino pensar el asunto a partir de ellos-. Ahora bien, Heidegger despoja este campo semántico de cualquier referencia a localización geográfica, no porque no mencione una localización, sino porque esta tiene una dimensión, quizá, más "lógica" que "física" 35 y, por lo tanto, porque lo que nombra ya no refiere a las fronteras ${ }^{36}$, sino a ese $l u$ gar de nuestro comportarnos, a ese "espacio-de-juegotemporal" de nuestro estar o ser en los asuntos que nos ocupan como lo que nos es familiar y nos da confianza, como nuestra costumbre y cotidianidad, esto es, a nuestro consistir en el "ahí", a nuestro carácter extático ${ }^{37}$. Este carácter extático, de ex-sistencia, es lo que querría decir, según Heidegger, que el hombre está "interpelado por el ser" 38 , esto es, por el "ser esto o lo otro" de aquello con lo que uno siempre está ya pre-ocupado y que se manifiesta como alguna lengua (alguna articulación discursiva), como lenguaje, en definitiva. Por consiguiente, que: "Sólo por esa llamada «ha» encontrado el hombre dónde habita su esencia. Sólo por ese habitar «tiene» el

Cf. GA 39, Hölderlin Hymnen "Germanien" und "Der Rhein", pp. 87-89, pp. 104-108 y pp. 120-123.

36 Incluso viene a desplazar el problema de la frontera a otro orden, a saber, el jurídico; un orden donde buscar la "nueva frontera" (la de un Estado-Nación que ahora mismo no existe) arguyendo lo que quieren decir aquí "patria" o "patria chica" ya solo podrá significar una denotada demagogia. La "patria" o la "patria chica" no tiene una frontera, porque no es nada "físico". Lo peor de pretender trazarla cuando esta, la "frontera", ya solo tiene sentido jurídico, no es el "nacionalismo" que lleva implícito, sino la ignorancia del nihilismo que demuestra; ignorancia que se manifiesta precisamente en confundir lo "físico" con lo "lógico" o si se quiere decir así, con lo "sentimental".

37 A propósito de lo que quiere decir "extático", cf. los parágrafos 11, 12 y 13 del curso de 1928 Principios metafísicos fundamentales de la lógica a partir de Leibniz, GA 26, pp. 203-280. La palabra refiere al modo como el ente que en cada caso somos es temporal, a saber, no en el sentido de algo "en" el tiempo, digamos, como un punto o un suceso en el continuo ilimitado "tiempo", sino como nuestro modo de ser. "Extático" está tomado de la expresión "éxtasis temporales" y refiere a nuestro estar o ser raptados por el tiempo, el que consistamos en un rapto de tiempo: "El éxtasis mencionado aquí, el salir de

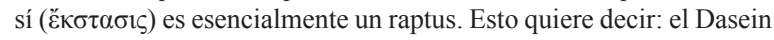
no se hace poco a poco un que tiene la expectativa gracias a que atraviesa, siguiendo una sucesión, el ente que fácticamente le viene a su encuentro como futuro, sino, al contrario, este atravesar recorre poco a poco únicamente el camino abierto por el raptus de la temporalidad misma. Esto vale análogamente para el retener y el hacer presente, $\mathrm{y}$, por tanto, denominamos a estos tres fenómenos fundamentales los éxtasis de la temporalidad. La temporalidad es ella misma la unidad extática que se unifica en la temporalización extática". M. Heidegger, Fundamentos metafísicos de la lógica, trad. J. J. García Norro, Madrid, Síntesis, 2008, p. 239 (cf. GA 26, pp. 265-266); para un estudio más detallado, cf. M. Jiménez Redondo, "Temporalidad e Historia en «Ser y Tiempo» de Martin Heidegger", Lapsus. Revista de psicoanálisis, 3, 5, 1995, pp. 61-74.

38 GA 9, Brief über den "Humanismus", p. 323. 
«lenguaje» a modo de morada que preserva el carácter extático de su esencia" "39; al cual Heidegger también se refiere como "estar en apertura a la verdad del ser" 40. Es, por tanto, el lenguaje el que "preserva" esa apertura, el que preserva, en definitiva, la estancia, el anthrópoi daímon. En Grecia, ese lenguaje es precisamente el del dicente experto en el sentido de que ese decir es el que se considera como "verdadero" decir, pues este es el decir cuidado, que pone de relieve el fondo, frente al decir trivial, que no saca a la luz ese fondo, que es descuidado, etc.

Pues bien, justamente es como lenguaje, como cabe, según leemos en Heidegger, que tengan lugar "leyes y normas" para "ordenar" el comportarse con las cosas ${ }^{41}$, esto es, como cabe que encontremos las "sentencias" que digan ese comportamiento, tal que, al decirlo, conformen estancia (êthos).

Solo en la medida en que el hombre pertenece ex-sistiendo a la verdad del ser, puede llegar del ser mismo la asignación [Zuweisung] de esas maneras de comportarse [o: instrucciones, Weisungen] que tienen que llegar a ser ley y regla para el hombre. Asignar [zuweisen, en el sentido de dar la instrucción, la regla, el reparto] se dice en griego véucıv. El vó $\mu$ o ̧ no es solo ley, sino más originariamente la asignación albergada en el destino [Schickung] del ser. Solo esta puede conjugar [verfügen] al hombre en el ser. Solo tal conjunción [Fügung] puede soportar [o: sostener, tragen] y vincular. De lo contrario, toda ley permanece solo en el dominio de la razón humana. Más esencial que todo establecimiento de reglas es que el hombre encuentre su estancia [Aufenthalt] en la verdad del ser. Únicamente esta estancia permite [o: concede, gewährt] la experiencia de lo estable [Haltbaren]. La verdad del ser regala [o: destina, verschenkt] el sostén [den Halt] para todo comportamiento [Verhalten]. "Sostén" $[$ Halt $]$ significa en nuestra lengua "protección" $[H u t]$. El ser es la protección que de tal manera en su verdad ampara [behütet $]$ al hombre en su esencia ex-sistente, tal que acoge [o: alberga, aloja, behaust la ex-sistencia en el lenguaje. Por eso, el lenguaje es a la vez la casa del ser y la morada $[B e-$ hausung] del hombre ${ }^{42}$.

\section{Ibidem.}

40 Con ello no solo se refiere a encontrarnos referidos a la "verdad" de esto o aquello, al "desocultamiento" de este ordenador en cuanto tal, de esta mesa, de este bolígrafo, etc., sino a la verdad de ese "desocultamiento" mismo, esto es, al "desocultamiento" del "ocultamiento", del venir a presencia de las cosas, o al "encubrimiento del desocultamiento" en el que consiste la "verdad" de cada cosa. Nos estamos refiriendo a la interpretación heideggeriana del fenómeno de la verdad que aparece recorrida en el texto De la esencia de la verdad (GA 9, pp. 177-202) y que viene a mostrar que al preguntar por el fenómeno de la verdad, por su esencia, ponemos de manifiesto que a ese fenómeno pertenece tanto lo que cotidianamente entendemos como "verdad" como lo que, también cotidianamente llamaos "no-verdad" (tanto aquello que llamamos "falso" como aquello que llamamos "error", "mentira", "engaño", etc.). El que a la "verdad" pertenezca también la "no-verdad" muestra, a su vez, que tan fenómeno de la verdad es la "cosa" ahí acontecida como el "quedar atrás" de su acontecer, es decir, que tan "verdad" es el que esa "cosa" sea desocultada, como el "ocultamiento" del desocultamiento mismo inherente a que cada cosa desocultada.

${ }^{41}$ Creemos que es aquí donde cabe situar la cuestión "política" en Heidegger, la cuestión de qué puede prescribirse jurídicamente y qué solo asignarse moralmente.

42 GA 9, Brief über den “Humanismus”, p. 360-361.
Con lo recorrido hasta aquí, parece que der $A u$ fenthalt está logrando decir eso que reconocemos que debía decir êthos sin que, al hacerlo, "pensemos en términos modernos". A partir de lo anterior -aunque, evidentemente, la discusión podría ser mucho más extensa-, se puede afirmar que ese êthos se reconoce, precisamente, allí donde se diga el comportarse, esto es, donde desde el lenguaje se lo haga comparecer en su presencia, o sea, donde se diga el hogar tal que, en ese mismo decir, comparezca, venga a la presencia por cuanto se lo esté reconociendo. Por ello, asimismo, es un dicente experto el que dice que: êthos anthrópoi daímon; que el venir a presencia del hombre es su estancia, esto es, su morar en o como lenguaje. Esta estancia viene a presencia en la medida en que se diga el nómos, la "norma", el "reparto", el "a cada uno su parte" y "a cada uno su lugar", por aquello que cada uno es, es decir, por el venir a presencia de cada cual. Este némein es como acontece la estancia misma, porque la estancia, el êthos, es el habitar o comportarse del hombre como aquel que "tiene el lenguaje" como su morada, que (puede) némein, que se da nómos, como su propio daímon. El némein es otro modo de decir excelente precisamente porque consiste en el establecimiento de ese reparto a partir del reconocimiento del "ser-cosa de cada cosa".

Así, en la medida en que el nómos dice precisamente el hogar, la patria, el suelo natal, constituye el contenido al cual se está vinculado de antemano, aquello a lo que uno pertenece y donde tiene su lugar propio, donde están "los de uno", etc. El nómos dice el venir a presencia mismo de aquello que hace hogar al hogar; el contenido que dice el nómos es, por tanto, el reconocimiento del propio vínculo. El nómos dice o reconoce ese vínculo en la medida en que establece isonomía, esto es, "ajustado reparto", "reparto" tal que una vez dado, conforma un "espacio-tiempo" que se rige por este nómos (por este juego o esta regla de juego) y no por las fuerzas arrolladoras de la intemperie, es decir, que construye un claro (Lichtung), una "cabaña", un "abrigo" que permite "proteger y custodiar" y de este modo establecer lo "conservable" para un "pueblo", para una comunidad. Esta comunidad lo es, insisto, por el mantenimiento de ese nómos, porque ese nómos la soporta, conformando el êthos que es anthrópoi daímon o sea, diciendo el sercosa de cada cosa no desde una "esfera" separada, sino desde cada cosa y como el comparecer de cada cosa.

Según esta interpretación, esto es lo que quiere decir que haya patria, a saber, que hay ese "espacio-de-juegotemporal" en el cual cada cosa tiene su lugar propio, su reparto, su asignación e instrucción, la cual viene "fijada" desde la cosa misma, es decir, desde su propio venir a presencia (como destino o envío del ser). De este modo es como pienso la patria desde los esfuerzos interpretativos de Heidegger.

\section{Die Heimatlosigkeit}

Pues bien, dijimos que el esfuerzo de pensar la patria tenía la vista puesta en pensar nuestro carácter apátrida. Para dar ahora este paso tenemos que considerar lo siguiente: 
El proyecto que trata de decir el nómos, de decir el contenido del vínculo, o sea, de reconocer el ser-cosa de cada cosa, es la pólis; y digo que trata de hacerlo porque el intento de hacer esto, de némein, va a comportar el hundimiento de eso mismo, ya que, como se apuntó en el tercer apartado, decir el ser, o sea, no una cosa, sino el "ser-cosa" de cada cosa, comporta el hundimiento mismo de ese decir, ya que comporta la fijación de ese ser $\mathrm{y}$, por tanto, que ya no-sea su venir a presencia, que eso mismo se pierda (o como lo diría Heidegger, conlleva el olvido del ser). Por consiguiente, el establecimiento del nómos es aquello que constituye, construye o reconoce el hogar, la patria, pero que en la medida en que consiste en decir precisamente el vínculo, esto es, aquello que hace hogar al hogar, es lo que nos conduce al desarraigo, a su pérdida.

Esto no lo he traído para desarrollarlo, sino para señalar un aspecto fundamental que se puede interpretar desde Heidegger, pero que, en mi opinión, se ha interpretado de un modo que arroja poca claridad a la cuestión. El aspecto fundamental es que el proyecto pólis es, en último término, un proyecto poético (de decir excelente), o sea, un proyecto que responde a la comprensión del lenguaje. Mi interpretación es que esta afirmación no pretende ser, en Heidegger, una propuesta de un programa político moderno, sino formar parte del esfuerzo interpretativo por poner de manifiesto nuestra distancia para con Grecia. En otras palabras, que este aspecto no hay que leerlo como "lo que hay que hacer en política hoy", sino como la diferencia entre lo que puede llamarse hoy "cuestiones políticas" y lo que puede llamarse hoy proyecto pólis (que, como se ve, es una manera de hablar de la situación griega antigua y no una "opción política").

Ahora bien, este aspecto sí quiere decir que solamente se reconoce hogar, patria, cuando el proyecto politico es poético (cuando se trata del proyecto pólis), aunque ello mismo implique el constante riesgo de perderla, y aunque tal proyecto esté abocado a la pérdida, al desarraigo. Por eso, Heidegger se plantea las "cuestiones políticas" a colación de "cuestiones poéticas" o de "lectura de poemas"; pero no para que nuestra política sea poéti$\mathrm{ca}^{43}$, sino para mostrar que, dado que no lo es, tampoco puede traernos o llevarnos de vuelta a patria ninguna y que eso, esa vuelta, en todo caso, la ofrecerá la poesía, no la política. Por esto mismo, cuando Heidegger piensa la patria siempre hay en juego la lectura de algún poema, pero de nuevo, no para construirla con ello, sino para mostrar que no la hay, que está perdida.

Por otro lado, precisamente, porque el proyecto pólis es un proyecto poético, puede argumentarse que es desde el lenguaje desde donde se puede notar nuestra diferencia con los griegos. Así, puede argumentarse que solo desde nuestra concepción moderna y metafísica del lenguaje -la cual no alcanza a comprender su fenomenalidad, sino que presupone el lenguaje como algo "ahí delante", algo para ser estudiado científicamente y que consiste en ser meramente una herramienta para la co-

$43 \quad$ Esta es la tesis defendida por Ph. Lacoue-Labarthe, La fiction du politique: Heidegger, l'art et la politique, Paris, Christian Bourgois, 1994, y es la tesis típica sobre este tema. municación- se entiende que pensar la patria consista, para nosotros, en pensar nuestro carácter apátrida, ya que:

Solo porque el lenguaje es la morada [Behausung] de la esencia del hombre, pueden los hombres y la humanidad histórica no estar en casa [nicht zu Hause sein] en su lenguaje, de modo que este sea la carcasa [Gehäuse] de sus maquinaciones $[\text { Machenschaften }]^{44}$.

O dicho de otro modo, nuestra diferencia con los griegos se entiende si pensamos en nuestro lenguaje, por cuanto este comparece en nuestro tiempo obliterado, decaído, es decir, porque nuestra concepción permite emplearlo como carcasa de nuestras maquinaciones, y esa misma concepción ignora que ello solo es posible porque la fenomenalidad del lenguaje consiste en ser "morada de la esencia del hombre" y no "herramienta para el dominio incondicionado de lo ente".

Dado que decir que el lenguaje es la carcasa de nuestras maquinaciones es otro modo de decir que el lenguaje se concibe como un instrumento para la dominación de lo ente, lo que se está reconociendo es que el lenguaje en nuestro tiempo está en función de la esencia de la técnica moderna ${ }^{45}$, esto es, de que las cosas se presenten como "existencias en stock" (Bestand), cosas en el intercambio general de todo con todo, por tanto, como mercancías, tal que nuestro trato con ellas es en la forma del "aprovechamiento" y la "explotación" de los

GA 9, 361, "Las características peculiares de la modernidad pueden rastrearse en la supremacía cada más generalizada y, sin embargo, discreta de la maquinación (der Machenschaft) y sus innumerables procesos técnicos, como, por ejemplo, la reducción continua a las existencias (Bestandes) bio-genéticas, la virtualización de la economía y el correspondiente poder del dinero, la formalización del derecho y el desvanecimiento de la política". S. Gorgone, "Machenschaft und Totale Mobilmachung: Heidegger Besinnung als Phänomenologie der Moderne", en Heidegger Studien, 22, 2006, pp. 49-69, aquí p. 56. Cf., asimismo, el trabajo de Alexandre Schild, "Machenschaft? - La tournure de fond en comble grecque ... de la seule et unique histoire-destiné [Geschichte] de l'estre ! (1 ${ }^{\text {èr }}$ partie)", en Heidegger Studien, 33, 2017, pp. 175-198 (donde se puede leer una crítica rigurosa a la lectura de Peter Trawin, cf. pp. 182-194) y "Machenschaft? - La tournure de fond en comble grecque ... de la seule et unique histoire-destiné [Geschichte] de 1'estre ! (2 ${ }^{\mathrm{ème}}$ partie)", en Heidegger Studien, 34, 2018, pp. 147-190. Por otro lado, y en un tono más afín al que aquí se sigue, cf. F. Duque, "Lo que resta de noche hasta el fin de las cosas", Sileno, 11, 2001, pp. 92-103.

45 A propósito de ello, afirma Bahr: "Tal vez lo notamos también como un problema de lenguaje: no sólo en el hecho de que puede reducirse a unas existencias [Bestand] facturables de señales y, por tanto, a una reserva de existencias [Bestand] de información, que tendría que producir representaciones en nosotros, sino también en el hecho de que casi nos deja hablar del poner [Stellen] como si se tratara más bien de un «hacer» [o: conducta, Tun] del hombre o de un acontecimiento sobre el que no tiene ninguna influencia. Sin embargo (como pretendía presentar), este «estar abandonado desde fuera» [Herausgesetztsein; o: estar expuesto] en el «centro» soñado del sujeto entre lo puesto y la realización de sus fines es característico de esa manejabilidad del medio que aumenta constantemente con el interminable «entorno [Umwelt] expandido» de lo que está disponible. En ello, lo puesto del poner se «disuelve» [zer-stellen] en una posibilidad de ser", H.-D. Bahr, "Das Wesen der Technik und das «andere Geschick». Ge-stell und Gegnet im Denken Martin Heideggers", op. cit., p. 107. Cf. M. Heidegger, Überlieferte Sprache und technische Sprache, hrsg. v. Hermann Heidegger. St. Gallen, Eker, 1989, para una lectura de este texto, cf. G. Kovacs, "Heidegger's Insight into the History of Language”, en Heidegger Studien, 29, 2013, pp. 121-132. 
"recursos", etc. Es otro modo de decir, por consiguiente, que nos encontramos en un sistema de producción capitalista, un sistema que aquello que produce en cada proceso de producción es siempre capital $^{46} \mathrm{y}$, por tanto, que nuestro punto de partida no es que decir las cosas sea reconocer su comparecencia (lo que hace la poiesis), sino que decir es "comunicar", "informar", intercambiar paquetes de información en el sistema mismo de producción.

Dado que en una situación histórica de estas características, el lenguaje es un medio para el normal funcionamiento del sistema productivo $\mathrm{y}$, en ese sentido, un arma, una herramienta que se esgrime y se aprovecha para que la producción de capital siga aumentando, difícilmente serán poéticos los proyectos políticos, ya que estos no tendrán entre manos la tarea de decir el hogar, sino, como mucho, de legislar la gestión del capital; pues la "política" siempre será "economía política".

Esto lo notamos en la medida en que para nosotros la "comparecencia" del comportarse ya no puede ser, por así decir, "inmediata"; nosotros nos encontramos envueltos, como parte de esa misma producción de capital, en un "decir" que no tiene por caso "válido" al poeta, sino al científico y al legislador, hasta el punto de que nuestro decir "trivial" no es descuidado porque no sea bello, cuidado, como el del poeta, sino porque no siempre es (o pretende ser) riguroso, como el del científico o el legislador; ni el científico ni el legislador hacen comparecer nuestro comportarnos, sino las garantías de que esta o aquella conducta pueda ser realizada, esto es, poder hacer sin referencia de antemano a los contenidos de lo que se pueda hacer. Y, sin embargo, es así como nos comportamos; nos comportamos en ese "conocer" $\mathrm{y}$ "legislar", en ese "producir capital", sin que esto signifique que en ello pueda reconocerse hogar, patria o suelo natal alguno. Resulta que nuestro "estado de derechos y garantías" (incluso aquel posible o pensable estado que fuese tal en un ajuste prácticamente exacto a la forma de derecho y a la forma ciencia) solo comparece en tanto que pérdida de la patria o del hogar, en tanto que seamos apátridas. Y debe ser así en la medida en que siga siendo precisamente de "derechos y garantías", es decir, ello mismo es la condición de la posibilidad para asegurar a cualquiera que podrá hacer, bajo las mismas condiciones, si quiere, lo mismo que cualquier otro ${ }^{47}$. ¿Qué consecuencias tiene este marco en relación con la

\footnotetext{
Además de los textos sobre Marx ya citados y del importante trabajo de Paloma Martínez Matías: "Producto y mercancía: sobre la constitución ontológica de la modernidad a partir de Heidegger y Marx", op. cit., cf. K. Axelos, Marx, pensado de la técnica, trad. E. Molina, Barcelona, Fontanella, 1959, del mismo: Introducción a un pensar futuro. Sobre Marx y Heidegger, Buenos Aires, Amorrortu, 1973 y S. Villalobos-Ruminott, "Marx-Heidegger: notas sobre la complementariedad entre destrucción y crítica del valor", en O. Cabezas, A. Fornazzari y E. Ansa (eds.), Crítica de la acumulación, Santiago de Chile, Escaparte-Universidad de Lagos, 2010, pp. 241-262.

47 Como se sabe, esta fórmula es de Martínez Marzoa y cabe preguntarse si tal cosa tiene lugar mientras la producción sea de capital, con todo lo que ello implica, y hasta qué punto, una y la otra cosa comportan y nos emplazan en una aporía. No voy a emprender esa discusión aquí. Simplemente se ha querido llegar a ella, y se ha llegado a ella desde Heidegger, es decir, ha sido con Heidegger que hemos trazado el marco para esa discusión, la cual, seguramente, empiece a requerir más textos que los de Heidegger.
}

cuestión de algo así como "tratar de fundar" o "construir" una "comunidad", es decir, el contenido mismo del hogar, de la patria, y así recuperarlo o algo por el estilo?

\section{A modo de cierre: ¿Recuperar?, ¿volver?, ¿llegar a ser?, ¿o perder?}

Por lo que respecta a los textos de Heidegger, sería bueno distinguir entre aquellos lugares en los que todavía se habla en términos de "fundar", "construir" o "reconstruir", y que refieren a algo así como "recuperar lo perdido" y aquellos en los que la cuestión es el Werden, el volverse a sentir o llegar a ser, efectivamente, heimisch (por tanto, el Heimischwerden), como en casa, pero que de todas formas es algo que aparece como un peregrinaje y no como un "programa político". Esta distinción se hace valer porque en lo primero, Heidegger demuestra no ser todo lo consecuente que se puede, incluso todo lo consecuente que él mismo podía ser para con lo que ya por aquel entonces (los años 30') se le estaba dando fenomenológicamente en su propio trabajo hermenéutico. Mientras que, en lo segundo, ese compromiso con la consecuencia es mayor, pero, evidentemente, hay en él cierta apuesta porque, de todas formas, algo vuelva o a algo se vuelva.

Sobre lo primero, que abarca la etapa del Rectorado y que se encuentra, especialmente, en los primeros años de los Cuadernos negros y en el primer curso sobre Hölderlin, hay que decir que esa pretensión solo puede llevar a un desmantelamiento del "estado de derechos y garantías", al tiempo que se cae en la ignorancia de la nihilidad, esto es, en la ignorancia del alcance del sistema de producción capitalista. En esto caen todos los nacionalismos, igual que caen todos los fundamentalismos (desde cuestiones específicamente de "conocimiento"), pues, en cierto modo, son lo mismo ${ }^{48}$. Heidegger abandona esta posición al tiempo que adopta una apuesta más radical. Esta apuesta más radical puede leerse en los textos del aquí llamado "primer momento" solamente siendo "benévolos" con Heidegger. A pesar de ello, es la lectura que resulta más viable e incluso filológicamente más coherente con el conjunto de su obra, ya que sí es lo que puede leerse en los textos del segundo momento.

Esa apuesta más radical estaría en la cuestión del volver, y abarca toda la trayectoria de Heidegger desde mediados de los años 30', más o menos a partir del curso Introducción a la metafísica y las conferencias sobre $\mathrm{El}$ origen de la obra de arte (aunque en estos dos textos hay todavía una fuerte ambigüedad para con esta cuestión) hasta el final de su obra. La fuerte ambigüedad de esos dos textos responde a que, en un primer momento, todavía aparece algo así como "fundar Estado", donde

\footnotetext{
Sería más larga la discusión sobre qué le ocurre a las "ideologías", es decir, hasta qué punto son motor, por ejemplo, de conquistas de derechos, o de la pérdida de estos, y hasta qué punto constituyen "útiles mascaradas" para una u otra cosa. Pero, en cualquier caso, esa discusión también demostraría que todas constituyen formas de ignorar el nihilismo, pues todas estarían echando mano del lenguaje precisamente como carcasa de maquinaciones.
} 
por "Estado" se sigue entendiendo hogar, patria, suelo natal, etc., pero ya se plantea como una efectiva vuelta al hogar (Heimkunft), aunque aún no se lo formule así. Sin embargo, finalmente, de esa vuelta al hogar queda excluida la posibilidad de que se traduzca en "Estado" $\mathrm{y}$, al mismo tiempo, tampoco hay concreción expositiva de en qué se pueda traducir. Por otro lado, aunque sí hay exposición de lo que puede significar, esta resulta tremendamente difícil de interpretar ya que se dirige insistentemente a la vuelta de ese daímon, a saber, la vuelta de lo sagrado, de la divinidad, la llegada del "último dios"49.

Queda pendiente una interpretación concienzuda de ello por nuestra parte. Sin embargo, pueden valorarse, al menos, las consecuencias que puede tener lo que se ha expuesto para con algo así como "tratar de fundar o construir una comunidad" y qué pueda significar esto, es decir, qué consecuencias puede tener lo expuesto para con las "cuestiones políticas" en y desde Heidegger. Lo que hemos expuesto se puede resumir diciendo que la patria se piensa para pensar nuestro carácter apátrida, no para construirla ni para fundar una nueva comuni$\operatorname{dad}^{50}$

Así, lo primero que puede extraerse es que el hogar, la patria, la comunidad, etc., no se presenta sino como lo perdido y, por consiguiente, la apuesta que parece más coherente con esa comparecencia -y, por tanto, con intentar asumir el nihilismo- es tratar de, por así decir, "perderlo del todo". Digamos que "perder" del todo el hogar y la patria quizá sea lo primero. La pérdida del hogar, desde el punto de vista público, lleva en marcha desde el siglo XIX, al menos si tenemos en cuenta que todo "Estado civil" rompe con lo que podemos llamar hogar, a saber, con el vínculo de antemano a la familia, el taller, el obispo, etc.; romper ese vínculo es perder el hogar. Pero ese mismo proceso ha estado conducido por la tendencia a tratar de ganar desde ahí la patria. Ahora bien, perder el hogar también implica una gran "desprotección", una instalación en la devastadora intemperie,

49 Sobre esta cuestión podemos especular, por ejemplo, acerca si podría ser ese volver a lo que apunta "el último dios". Pero dada la vaguedad de la formulación heideggeriana, o hay que resignarse a admitir que no se puede sostener con firmeza mucho sobre ello, o que quizá hay que esperar a que haya más trabajo filológico y de crítica textual sobre el texto que permite algún acercamiento coherente y cuerdo para con esta cuestión. Lo que nos parece que no tiene cordura es plantear que hay en Heidegger proyectos de mitificación política o cosas por el estilo, pues si se trata de ello, entonces, quizá haya que reconocer que no hay cuestión en esos textos de Heidegger, y este no parece ser el caso. Creemos que Paloma Martínez Matías, en su trabajo: "Entre dioses y hombres: para una interpretación del problema de la divino y lo sagrado en el pensamiento de Martin Heidegger". Anales del seminario de historia de la filosofia, 31, 1, 2014, pp. 155-176, plantea las líneas generales de una interpretación "cuerda" de esta cuestión. Cordura que, por ejemplo, quizá resulta más complicada de encontrar (y en cualquier caso se presenta de un modo más problemático) en otros trabajos, como, por ejemplo, en el texto de Christian Sommer, Mythologie de l'événement. Heidegger avec Hölderlin, Paris, PUF, 2017.

50 Lo decimos, precisamente, frente a autores como Roberto Esposito, Nancy (cf. R. Esposito, Communitas. Origen y destino de la comunidad, trad. Carlo Rodolfo Molinari Marotto, Buenos Aires, Amorrortu Editores, 2003) e incluso Agamben que insisten en esto; G. Agamben, La comunidad que viene, trad. J. L. Villacañas y C. La Rocca, Valencia, Pre-Textos, 1996. la cual se impone en las distintas transformaciones que el sistema de producción capitalista ha ido sufriendo o que ha hecho sufrir a la población mundial en mayor o menor medida y en unas $\mathrm{u}$ otras esferas en función de la situación geográfica y socioeconómica (y jurídica) de partida de los individuos.

Pero si todavía se impone esa devastadora intemperie (el crecimiento del desierto) es porque todavía se albergan desiertos, es decir, porque todavía no se quiere perder el hogar del todo, porque todavía no se está dispuesto a perderlo, lo cual, políticamente se expresa en la pretensión de que esa pérdida sea el espacio para ganar la patria, la comunidad, etc., a pesar de que no podemos saber, ni pensar, en qué consistiría ganarla o haberla ganado, puesto que aún nos encontramos en la situación de tener que reconocer nuestro haberla perdido. Insisto, lo que cabe ante esto es ser capaz de soportar la pérdida y perder por fin tanto el hogar como la patria, o sea, asumir nuestro carácter apátrida.

Ahora bien, es esto lo que puede constatarse que públicamente no ocurre. Digamos que "moralmente" (allí donde el derecho no llega) esto no se impone, sino que se impone más bien la reactividad o la pasividad, la ausencia de capacidad para soportar, y con ello la ignorancia de la pertenencia al nihilismo, a la Heimatlosigkeit, al haber siempre ya perdido el hogar, que se expresa en las distintas formas con las que en nuestros días se arguye que la "estrategia", la "política" debe estar al servicio de la comunidad, la patria, el pueblo (la gente), etc., y que se opone a aquella política, quizá menos altisonante (y seguramente también nihilista, pero en otro sentido) que trata de dirigirse a los ciudadanos, a los miembros del estado civil, despojados de particularidades e igualados (homologados y allanados) por la ley. Pues bien, a esa "política de la patria, la comunidad, el pueblo, la gente, etc." decimos lo siguiente:

No dice nada decir que hay una "comunidad de los que no tienen comunidad"; esos, los que no tienen comunidad, pueden intentar tener "estado civil" -lo cual, seguramente, tampoco va a llegar con toda la fuerza que haría falta para que el sistema llegase a ser social y no capitalista- si esos mismos asumen la pérdida del hogar. La "comunidad" que seguimos pensando es la misma que se piensa como hogar, como patria, como eso que no acontece sino como lo perdido. Y seguirá siendo así mientras eso mismo no lo perdamos del todo. Quizá, perdido del todo, surja algo que, entonces, visto desde estas categorías, llamaríamos "comunidad". La cuestión es que esta no se "funda", ni se "construye", sino que surge y ello depende de que se termine de perder lo que hay, lo cual no solo comporta que eso que surja no será como lo pensamos, sino que seguramente tampoco tendrá porqué seguir mencionándose como lo haríamos nosotros. Ahora bien, lo que vendrá solo son apuestas y, desde luego, no es de lo que uno debe preocuparse, pues insisto, todo ello está necesariamente bloqueado en la medida que la pérdida no se asuma como tal. Asumir la pérdida sigue siendo por tanto la cuestión, y este "asumir" no cabe, por definición, en ningún "programa político", que es otro modo de decir que nuestros proyectos políticos ya no son (ni pueden ser) poéticos sino que, en todo caso, pueden caer en ser retóricos, es decir, en pretender algo que, por definición, ya no se puede. 


\section{Bibliografía}

Agamben, G., La comunidad que viene, trad. J. L. Villacañas y C. La Rocca, Valencia, Pre-Textos, 1996.

Axelos, K., Marx, pensado de la técnica, trad. E. Molina, Barcelona, Fontanella, 1959.

-, Introducción a un pensar futuro. Sobre Marx y Heidegger, Buenos Aires, Amorrortu, 1973.

Bahr, H.-D., "Das Wesen der Technik und das «andere Geschick». Ge-stell und Gegnet im Denken Martin Heideggers", en Heidegger Studien, 29, 2013, pp. 89-120.

Borges-Duarte, I., "La tesis heideggeriana acerca de la técnica", Anales del Seminario de Historia de la Filosofia, 10, 1993, pp. 121-156.

-, Arte e técnica em Heidegger, Rio de Janeiro, Via Verita, 2019.

Derrida, J., Spectres de Marx, Paris, Éditions Galilée, 1993.

Duque, F., "Lo que resta de noche hasta el fin de las cosas", Sileno, 11, 2001, pp. 92-103.

-, El cofre de la nada: deriva del nihilismo en la modernidad, Madrid, Abada Editorial, 2006.

Esposito, R., Communitas. Origen y destino de la comunidad, trad. C. R. Molinari Marotto, Buenos Aires, Amorrortu Editores, 2003.

Fasolino, R. C., "De las (im)posibilidades del vínculo. Algunas consideraciones a partir del «discurso del capitalista» de J. Lacan", inédito.

Fernández Liria, C. y Alegre Zahonero, L., El orden de El Capital. Por qué seguir leyendo a Marx, Madrid, Akal, 2010.

Gorgone, S., "Machenschaft und Totale Mobilmachung: Heidegger Besinnung als Phänomenologie der Moderne", en Heidegger Studien, 22, 2006, pp. 49-69.

Heidegger, M., Gesamtausgabe, Bd. 2, Sein und Zeit, Frankfurt am Main, Vittorio Klostermann, 1977.

-, Gesamtausgabe, Bd. 5, Holzwege, Frankfurt am Main, Vittorio Klostermann, 1977.

-, Gesamtausgabe, Bd. 26, Metaphysische Anfangsgründe der Logik im Ausgang von Leibniz, Frankfurt am Main, Vittorio Klostermann, 1978.

-, Gesamtausgabe, Bd. 4, Erläuterungen zu Hölderlins Dichtung, Frankfurt am Main, Vittorio Klostermann, 1981.

-, Gesamtausgabe, Bd. 9, Wegmarken, Frankfurt am Main, Vittorio Klostermann, 1976.

-, Gesamtausgabe, Bd. 55, Heraklit. 1. Der Anfang des abendländischen Denkens. 2. Logik. Heraklit Lehre vom Logos, Frankfurt am Main, Vittorio Klostermann, 1979.

-, Gesamtausgabe, Bd. 39, Hölderlins Hymnen “Germanien” und “Der Rhein”, Frankfurt am Main, Vittorio Klostermann, 1980.

-, Gesamtausgabe, Bd. 54, Parmenides, Frankfurt am Main, Vittorio Klostermann, 1982.

-, Gesamtausgabe, Bd. 40, Einführung in die Metaphysik, Frankfurt am Main, Vittorio Klostermann, 1983.

-, Gesamtausgabe, Bd. 53, Hölderlins Hymne "Der Ister”, Frankfurt am Main, Vittorio Klostermann, 1984.

-, Gesamtausgabe, Bd. 12, Unterwegs zur Sprache, Frankfurt am Main, Vittorio Klostermann, 1985.

-, Gesamtausgabe, Bd. 15, Seminare, Frankfurt am Main, Vittorio Klostermann, 1986.

-, Gesamtausgabe, Bd. 65, Beiträge zur Philosophie (Vom Ereignis), Frankfurt am Main, Vittorio Klostermann, 1989.

-, Überlieferte Sprache und technische Sprache, St. Gallen, Eker, 1989.

-, "Die Armut", en Heidegger Studien, 10, 1994, pp. 5-11.

-, Gesamtausgabe, Bd. 7, Vorträge und Aufsätze, Frankfurt am Main, Vittorio Klostermann, 2000.

-, Gesamtausgabe, Bd. 16, Rede und anderen Zeugnisse eines Lebensweges, Frankfurt am Main, Vittorio Klostermann, 2000.

-, Gesamtausgabe, Bd. 90, Zu Ernst Jünger, Frankfurt am Main, Vittorio Klostermann, 2004.

-, Ser y tiempo, trad. J. E. Rivera, Madrid, Trotta, 2009.

-, Fundamentos metafísicos de la lógica, trad. J. J. García Norro, Madrid, Síntesis, 2008.

-, Gesamtausgabe, Bd. 73.1, Zum Ereignis-Denken, Frankfurt am Main, Vittorio Klostermann, 2013.

-, Gesamtausgabe, Bd. 94, Überlegungen II-IV (Schwarze Hefte 1931-1938), Fankfurt am Main, Vittorio Klostermann, 2014.

-, Hitos, trad. H. Cortés y A. Leyte, Madrid, Alianza Editorial, 2014.

Heinrich, M., ¿Cómo leer El Capital de Marx? Indicaciones de lectura y comentario del comienzo de El Capital, trad. C. Ruiz Sanjuán, Madrid, Guillermo Escolar, 2018.

Hölderlin, F., Sämtliche Werke "Frankfurter Ausgabe”, Historisch-kritische Ausgabe herausgegeben von D. E. Sattler, Band 19, Stammbuchblätter, Widmungen und Briefe II, hrsg. v. D. E. Sattler und Anja Ross, Frankfurt am Main, Stroemfeld Verlag, 2007.

Janicaud, D., L'ombre de cette pensé - Heidegger et la question politique, Grenoble, J. Millon, 1990.

Kovacs, G., "Heidegger's Insight into the History of Language", en Heidegger Studien, 29, 2013, pp. 121-132.

Lacoue-Labarthe, Ph., La fiction du politique: Heidegger, l'art et la politique, Paris, Christian Bourgois, 1994.

Martínez Matías, P., "Producto y mercancía: sobre la constitución ontológica de la modernidad a partir de Heidegger y Marx", Logos: Anales del Seminario de Metafísica, 47, 2014, pp. 199-225.

-, "De la «pólis» al estado moderno: una aproximación al problema de lo político en Heidegger", Anales del seminario de historia de la filosofia, 32, 2, 2015, pp. 451-475.

-, "La cuestión política en el capitalismo neoliberal global”, Res Publica: revista de historia de las ideas políticas, 22, 2, 2019, pp. 511-531.

Martínez Marzoa, F., De Grecia y la Filosofia, Murcia, Secretariado de Publicaciones, Universidad de Murcia, 1990.

-, Historia de la filosofía antigua, Madrid, Akal, 1995.

-, Ser y diálogo. Leer a Platón, Madrid, Itsmo, 1996.

-, El saber de la comedia, Madrid, Antonio Machado Libros, 2005.

-, El decir griego, Madrid, Antonio Machado Libros, 2006.

-, La filosofia de "El capital" de Marx, Madrid, Abada, 2018.

-, El concepto de lo civil, Madrid, La Oficina, 2018. 
Nieto, M., Cómo funciona la economía capitalista, Madrid, Escolar y Mayo, 2015.

Ramas San Miguel, C., Fetiche y mistificación capitalistas. La crítica de la economía política de Marx, Madrid, Siglo XXI, 2018. Ricci, F., "Gagner la Heimatlosigkeit”, en Heidegger Studien, 24, 2008, pp. 61-102.

Ruiz Sanjuán, C., Historia y sistema en Marx. Hacia una teoría crítica de El capital, Madrid, Siglo XXI, 2019.

Santos Guerrero, J., Cuestiones de marco. Estética, política y deconstrucción, Madrid, Escolar y Mayo Editores, 2014.

Schalow, F., "The «Ownmost Sway» of Technicity and Its Hermeneutic Guideline (Part I)”, Heidegger Studien, 29, 2013, pp. 5166.

-, “A Look at Recent Literature on Technicity, Machination, and the Turning: Part II”, en Heidegger Studien, 30, 2014, pp. 7995.

Schild, "Machenschaft? - La tournure de fond en comble grecque ... de la seule et unique histoire-destiné [Geschichte] de l'estre! (1 ${ }^{\text {èr }}$ partie)", en Heidegger Studien, 33, 2017, pp. 175-198.

-, "Machenschaft? - La tournure de fond en comble grecque ... de la seule et unique histoire-destiné [Geschichte] de l'estre ! ( $2^{\text {ème }}$ partie)", en Heidegger Studien, 34, 2018, pp. 147-190.

Schmidt, J., Ethos. Beiträge zum antiken Wertempfinden, Borna, 1944.

Sommer, Ch., Mythologie de l'événement. Heidegger avec Hölderlin, Paris, PUF, 2017.

Schürmann, R., Le principe d'anarchie: Heidegger et la question de l'agir, París, Seuil, 1982.

Vázquez, M. E., "Heidegger-Hölderlin / Filosofía-política", en J. Marrades y M. E. Vázquez (eds.), Hölderlin. Poesía y pensamiento, Valencia, Pre-Textos, 2001, pp. 163-176.

Villalobos-Ruminott, S., "Marx-Heidegger: notas sobre la complementariedad entre destrucción y crítica del valor", en O. Cabezas, A. Fornazzari y E. Ansa (eds.), Crítica de la acumulación, Santiago de Chile, Escaparte-Universidad de Lagos, 2010, pp. 241-262.

Vietta, S. Heideggers Kritik am Nationalsozialismus und an der Technik, Tübingen, Niemeyer, 1989.

Volpi, F., “«Noi senza patri». Heidegger e la «Heimatlosigkeit» dell'uomo moderno”, Revista Portuguesa de Filosofia, 59, 4, 2003, pp. 1261-1263.

-, Nihilismo, trad. C. I. del Rosso y A. Vigo, Buenos Aires, Editorial Biblios, 2005. 